DOE/ID/12778-1

(DE92016807)

SIMULATION OF ETHYLEENZENE DEHYDROGENATION IN MICROPOROUS CATALYTIC MEMBRANE REACTORS

Toplcal Report

April 1989

Work Performed Under Contract No. FC07-881012778

For

U.S. Department of Energy

Office of Indusirial Technologies

Washington, D.C.

By

Alcoa

Warrendale, Pennsylvania 


\section{DISCLAIMER}

This report was prepared as an account of work sponsored by an agency of the United States Gavernment. Neither the United States Government nor any agency thereof, nor ary of their employees, makes any warranty, express or implied, or assumes any legal liability or re iponsibility for the accuracy, completeness, or usefulness of any information, apparatus, produc , or process disclosed, or represents that its use would not iniringe privately owned rights. Refezence herein to any specific commercial product, procuss, or service by trade name, trademark, manufacturer, or otherwise does not necessarily constitute or imply its endonsement, recominendation, or favoring by the United States Government or any agency thereof. The views and opinions of authors ex pressed herein do not necessarily state or reflect thase of the United States Government or any agerncy thereof.

This report has been reproduced directly from the best available copy.

Available to DOE and DOE contractors from the Office of Scientific and Technical Information, P.O. Box 62, Oak Ridge, TN 37831; prices available from (615)576.8401.

Available to the public from the National Technical Information Service, U.S. Department of Commerce, 5285 Port Royal Rd., Springfield, VA 22161. 


\title{
SIMULATION OF ETHYLBENZENE DEHYDROGENATION IN MICROPOROUS CATALYTIC MEMBRANE REACTORS
}

\section{Topical Report}

April 1989

Work Performed Under Contract No. DE-FC07-88ID12778

\author{
Prepared for the \\ U.S. Department of Energy \\ Under DOE Idaho Field office \\ Sponsored by the office of the Assistant Secretary \\ for Conservation and Renewable Energy \\ office of Industrial Technologies \\ Washington, D.C. \\ Prepared by \\ Alcoa \\ Separations Technology Division \\ 181 Thorn Hill Road \\ Warrendale, Pennsyivania 15086
}




\section{TABLE OF CONTENTS}

Prge

1. Abstract of Program............................................................ 1

2. Technical Highlights ......................................................... 2

3. Introduction.....................................................................

4. Mathematical Model ............................................................... 3

4.1 Material Balance ............................................................... 3

4.2 Chemical Reaction............................................................. 4

4.3 Knudsen Diffusion.......................................................... 5

4.4 Poiseuille Flow ................................................................ 6

5. Computer Algorithm ........................................................... 6

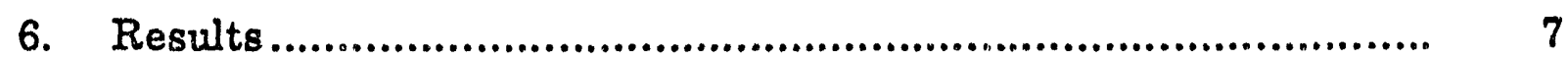

7. Numerical Method............................................................. 7

8. Discussions....................................................................... 8

9. Limitations of Model ........................................................ 8

9.1 Side Reactions ........................................................... 8

9.2 Isothermal Condition..................................................... 8

9.3 Validity of Knudsen Diffusion..............................................

9.4 Local Equilibrium Conversion.......................................... 9

10. References .................................................................. 9

11. Tables \& Figures................................................................ 11-23

12. Appendix .................................................................... 25.29 


\section{LIST OF TABLES AND FIGURES}

Table 1 Critical Properties and Operation Conditions

Table 2 Composition of Membrane Separation

Table 3 Composition of Membrane Separation with Permeate Vacuum

Table 4 Mean Free Path at 1 atm

Figure 1 Separation of Membrane Reactor into " $n$ n Number of Stages

Figure 2 Material Balance of Given Stage, $j$

Figure 3 Flow Chart of Computer Program

Figure 4 Sectional Calculation Diagram

Figure 5 The Effect of Surface Area on Ethylbenzene Dehydrogenation $40 \AA$ Membrane, $T=900^{\circ} \mathrm{K}, \mathrm{P}=1.5 \mathrm{~atm}, \mathrm{~V}=0.03 \mathrm{M}^{3} / \mathrm{s}, \mathrm{EB}=20 \%$

Figure 6 Temperature Effect on Ethylbenzene Dehydrogenation 40\& Membrane, $P=1.5$ atm, $V=0.03 \mathrm{M}^{3} / \mathrm{s}, \mathrm{EB}=20 \%$

Figure 7 Pressure Effect on Ethylbenzene Dehydrogenation $40 \AA$ Membrane, $T=900^{\circ} \mathrm{K}, \mathrm{V}=0.03 \mathrm{M} 3 / \mathrm{s}, \mathrm{EB}=20 \%$

Figure $8 \quad \mathrm{~N}_{2}$ Diluent Effect on Ethylbenzene Debydrogenation $40 \AA$ Membrane, $T=900^{\circ} \mathrm{K}, P=1.5$ atm, $V=0.03 \mathrm{M}^{3} / \mathrm{s}$

Figure 9 Convergence Test of Simulation $\mathrm{T}=900^{\circ} \mathrm{K}, \mathrm{P}=1.5 \mathrm{atan}, \mathrm{V}=0.03 \mathrm{M}^{3} / \mathrm{s}, \mathrm{EB}=20 \%, \mathrm{~A}=0.5 \mathrm{M}^{2}$ 


\section{ABSTRACT OF PROGRAM}

Current state-of-the-art inorganic axide membranes offer the potential of being modified to yield catalytic properties. The resulting modules may be configured to simultaneousiy induce catalytic reactions with product concentration and separation in a single processing step. Processes utilizing such catalytically active membrane reactors have the potential for dramatically increasing vield of reactions which are currently limited by either thermodynamic equilibria, product inhibition, or kinetic selectivity. Examples of systems of commercial interest include hydrogenation, dehydrogenation, partial and selective oxidation, hydrations, hydrocarbon cracking, olefin metathesis, hydroformylation, and olefin polymerization. A large portion of the most significant reactions fall into the category of high temperature, gas phase chemical and petrochemical processes. Microporous oxide membranes are well suited for these applications.

A program is proposed to investigate selected model reactions of commercial interest (i.e., dehydrogenation of ethylbenzene to styrene and dehydrogenation of butane to butadiene) using a high temperature catalytic membrane reactor. Membranes will be developed, reaction dynamics characterized, and production processes developed, culminating in laboratory.scale demonstration of technical and economic feasibility.

As a result of the anticipated increased yield per reactor pass, large economic incentives are envisioned. First, a large decrease in the temperature required to obtain high yield should be possible because of the reduced driving force requirement. Signic cantly higher conversion per pass implies a reduced recycle ratio, as well as reduced reactor size. Both factors result in reduced capital costs, as well as savings in cost of reactants and energy. Moreover, the controlled, defined reaction zone (the membrane interface), will facilitate the reactor design process and permit greater control of reactor dynamics, including mass and heat transfer (both of which will now be convective, rather than conductive) should result in more efficient reactor control and design. Lower reactor temperatures also imply possibly less stringent catalyst requirements, as well as the potential to carry out reactions directly that were previously multi-step. Because of the unnumerable reactions of commercial interest in the chemical process industries fall into these categories, commercial impact could be enormous. 


\section{TECHNICAL HIGHLIGHTS}

A mathematical model describing dehydrogenation of ethylbenzene to styrene with membrane reactors has been developed. The model has been established by incorporating thermodynamic equilibrium of the reaction with gas permeution through microporous ceramic membranes. This model has been used to simulate the conversion ratio of the dehydrogenation for a wide range of temperature and pressure.

The use of membrane zeactors can achieve a $>90 \%$ conversion which is substantially higher than the theoretical equilibrium ratis of $66 \%$ at a typical operating condition (i.e., $900 \%$ and 1.5 atm containing $20 \%$ of ethylbenzene in the feed). This degree of enhanced conversion would reduce significant energy requirement in the down stream product separations. Additional advantages in hardware and catalyst materials can be achieved and were identified in the previous quarterly report.

The effect of operating conditions, such as temperature, pressure, and diluent ratio in a membrane reactor, has been studied. The faverable condition for the traditional reactor, i.e., high tempereture and low pressure, is applicable for the use of membrane reaciors. An experimental plan will be developed for verification with a laboratory reactor, which will be the focus of the study in the third quarter.

Once the experimental data becomes available, the mathematical model developed here will be modified to take into account the non-ideal situations, such as side reactions, and incomplete local thermodynamic equilibrium. The model will then be used for process development and optimization, which will be conducted in the second and third year. 


\section{INTRODUCTION}

A mathematical model has been developed to simulate the dehydrogenation of ethylbenzene to styrene with microporous ceramic membrane reactors. The simulation outcome will (1) demonstrate the degree of conversion improvement, and (2) provide directions on our experimental program. After comparing with the experimental results, this simulation program will be modified in order to precisely describe the catalytic conversion process with microporous ceramic membranes. The ultimate goal of this work is to provide the basis for process development and optimization in the second and third year of this research program.

\section{MATHEMATICAL MODEL}

The mathematical model is developed by incorporating gas permeation through microporous ceramis membranes with catalytic reactions. Gas permeation has been discussed in detail in the first quarterly report, which includes Knudsen diffusion, and Poiseuille flow. Assumptions made for developing the mathematical model are listed as follows:

- Gas permeation through surface diffusion is negligible. The catalytic reaction we are pursuing is operated at a low pressure and high temperature environment.

- Ideal gas law is used to describe the gas behavior of single components and gas mixtures. The suitable operating condition for ethylbenzene dehydrogenation is in the moderate high temperature $\left(400\right.$ to $\left.650^{\circ} \mathrm{C}\right)$ and low pressure $(0$ 2 atms). Ideal gas law appears adequate according to the compressibility factor determined for each component listed in Table 1.

- An isothermal condition is assumed through the entire calculation. Dehydrogenation of ethylbenzene is endothermic, which requires to supply the heat to maintain the isothermal concition.

- A simple dehydrogenation of ethylbenzene to styrene and hydrogen is studied in this model. No side reactions are considered.

\subsection{Material Balance}

The tubular membrane reactor is separated into a " $n$ " number of continuous stirred tank reactors as shown in Figure 1. Material balance is imposed upon each reactor as illustrated in Figure 2. 
For a given reactor, $j$,

Reject, $j,=$ Feed, $j$, Permeate, $j,+$ Chemical Reaction, $j$,

$$
R_{j}=F_{j}-P_{j}+\Delta x_{j}
$$

and,

$$
P, j=\left(Q_{k}+Q_{p}\right) \cdot \Delta P \cdot A
$$

where $Q_{k} \quad$ permeability contributed by Knudsen diffusion Qp permeability contributed by Poiseuille flow $\triangle \mathrm{P} \quad$ pressure drop across transmembrane A effective surface area for permeation

Estimation of $Q_{k}, Q_{p}$, and $\Delta x$ is discussed individually in the following sections.

\subsection{Chemical Reaction}

$$
\begin{aligned}
& \mathrm{Kp}=\frac{\mathrm{P}_{\mathrm{H} 2} \cdot \mathrm{P}_{\mathrm{ST}}}{\mathrm{P}_{\mathrm{EB}}} \\
& \mathrm{EB}+\mathrm{N}_{2} \rightarrow \mathrm{H}_{2}+\mathrm{ST}+\mathrm{N}_{2}
\end{aligned}
$$

$\begin{array}{llllll}\text { Initial } & x & n & y & z & n \\ \text { equilibrium } & x-\Delta x & n & y+\Delta x & z+\Delta x & n \\ \text { T'otal moles } & =x+y+z+\Delta x & \therefore & \end{array}$

Assuming ideal gas, Pt: total pressure

$$
\begin{aligned}
& P_{E B}=\left(\frac{x-\Delta x}{x+y+z+\Delta x+n}\right) P t \\
& P_{S T}=\left(\frac{z+\Delta x}{x+y+z+\Delta x+n}\right) P t \\
& P_{H 2}=\left(\frac{y+\Delta x}{x+y+z+\Delta x+n}\right) P t
\end{aligned}
$$




$$
\begin{aligned}
& P_{N 2}=\left(\frac{n}{x+y+z+\Delta x+n}\right) P t \\
& K p=\frac{\left(\frac{y+\Delta x}{x+y+z+\Delta x+n}\right) P t\left(\frac{z+\Delta x}{x+y+z+\Delta x+n}\right) P t}{\left(\frac{x-\Delta x}{x+y+z+\Delta x+n}\right) P t} \\
& \left(1+\frac{K p}{P t}\right) \cdot \Delta x^{2}+\left(\frac{K p}{P t} \cdot(y+z+n)+(y+z)\right) \cdot \Delta x- \\
& \left(\frac{K p}{P t}\right) \cdot x \cdot(x+y+z+n)+y z=0
\end{aligned}
$$

The styrene and hydrogen production $(\Delta x)$ can be calculated by solving the equation 10. The chemical equilibrium constants can be found in the literature [1].

\subsection{Enudsen Diffusion [2]}

$$
\begin{aligned}
& \mathrm{D}_{\mathrm{k}}=\frac{2}{3} \mathrm{r} \cdot \sqrt{\left(8000 \cdot \mathrm{R} \cdot \frac{\mathrm{T}}{(\tau \cdot \mathrm{M})}\right)} \\
& \mathrm{Q}_{\mathrm{k}}=\frac{\varepsilon_{\mathrm{p}} \cdot \mathrm{D}_{\mathrm{k}}}{\tau \cdot \mathrm{R} \cdot \mathrm{T} \cdot \mathrm{L}}
\end{aligned}
$$

$$
\begin{aligned}
& \text { where: } r \text { pore radius, } M \\
& \mathrm{~T} \text { temperature, } \mathrm{K} \\
& \text { R gas constant, 8.313 (Pa-M3) (1/g-mole) (1/K) } \\
& \text { M molecular weight, g/mole } \\
& D_{k} \quad \text { Knudsen effective diffusivity, } M^{2} / 8 \\
& \mathrm{Q}_{\mathrm{k}} \text { Kaudsen permeability, g-mole/(Pa-M2-s) } \\
& \varepsilon p \quad \text { porosity of membrane layer } \\
& \tau \text { tortuosity } \\
& \text { L permselective layer thickness, M }
\end{aligned}
$$

In the Knudsen regime, each species diffuses independently so that the diffusivity does not depend on either composition or total gas concentration. 


\subsection{Poiseuille Flow [2]}

$$
Q p=\frac{10 \cdot \varepsilon_{p} \cdot P \cdot r^{2}}{8 \cdot \mu \cdot \tau \cdot R \cdot T \cdot L}
$$

where: $\mathrm{P}$ pressure, $\mathrm{Pa}$

$\mu \quad$ viscosity, $\mathrm{Pa-s}$, or, poise/10

Gas viscosity is required for the estimation of Poiseuille flow. It is the function of temperature and pressure. Viscosity at low pressure is estimated by using the theoretical Hirschfelder method which was further modified by Bomley and Wilke [3].

$$
\begin{aligned}
\mu^{0} & =\frac{33.3 \cdot(M T c)^{0.5}}{V c^{0.333}}(f(1.33 T r)) \\
f(1.33 T r) & =1.058 \cdot T r^{0.645}-\frac{0.261}{(1.9 \cdot T r)^{0.9 \cdot \log (1.9 \cdot T r)}}
\end{aligned}
$$

where: $\mu^{\circ}$ viscosity at low pressure, micropoise

Tc critical temperature, $\mathbb{K}$

Tr reduced temperature

Vc critical volume, mlg-mole

\section{COMPUTER ALGORITHM}

Figure 3 presents the flow chart of the computer program. The input data are divided into four groups: (a) gas component, molecular weight, and its dipole moment; (b) critical temperature, critical pressure, critical density, and reaction equilibrium constant; (c) membrane porosity, tortuosity, pore radius, thickness, reactor number in calculation, total surface area; and (d) total flow rate, operation temperature and pressure, and feed composition.

The surface area of each reactor is calculated by dividing the total surface area with the input number of reactors, NS. The computation is then carried out reactor by reactor. Figure 4 shows the calculation diagram. For a given reactor, reaction conversion is first calculated, and then, product separation is estimated from Knudsen diffusion and Poiseuille flow. The composition of permeate and reject is computed by mass balance. The flow rate and composition of reject are assigned as the feed to the next subsequential reactor. The computer program and a typical input data are listed in the appendix.

Two operating conditions are identified in the permeate side (Figure 4). One condition is operated without vacuum in the permeate side. The permeate species are accumulated in the permeate side. The repeated calculation continues till the 
last reactor is encountered. The other is operated with vacuum to the permeate side. Thus, a significant pressure drop across the membrane is maintained in every reactor. Finally, the species of permeate in each reactor are added together as the total permeate output. It is anticipated that the field operation would approximate the latter condition.

\section{RESULIS}

Tables 2 and 3 give the flow rate and composition of permeate and reject for the two conditions. Nitrogen is used as inert diluent. The volume flow rate $\left(0.03 \mathrm{M}^{3} / \mathrm{s}\right)$ is messured at the simulation temperature. The feed composition is kept at $20 \%$ ethylbenzene balanced with nitrogen which is in the proximity of the feed partial pressure in the commercial operation. The conversion is calculated by the following equation:

$$
\text { Conversion }(\%)=\frac{\text { styrene in permeate }+ \text { styrene in reject }}{\text { ethylbenzene in feed }} \cdot 100 \%
$$

Figure 5 shows that the reaction conversion is enhanced by using membranes under a typical operating condition, e.g., $900^{\circ} \mathrm{K}, 0.03 \mathrm{M} 3 / \mathrm{s}$ of feed with $20 \%$ ethylbenzene in nitrogen. About $12.5 \%$ above the equilibrium conversion can be achieved at the mid-point of the membrane tube, i.e., at $0.6 \mathrm{M}^{2}$, for the condition withnut vacuum. Membrane $>0.6 \mathrm{M}^{2}$ does not provide any additional enhancement. The conversion is even higher, i.e., $>90 \%$, when vacuum is performed in the permeate side. The temperature effect is shown in Figure 6. Since ethylbenzene dehydrogenation is endothermic, a high temperature condition is favorable for this reaction. At $700 \% \mathrm{~K}, 5 \%-10 \%$ above the aquilibrium conversion is achieved with membrane reactors. While $12 \%$ 22\% is achieved at $900^{\circ} \mathrm{K}$. Figure 7 illustrates the influence of total pressure on this reaction. The lower the total pressure, the higher the conversion. The effect of nitrogen diluent, or partial pressure of ethylbenzene, is shown in Figure 8. It has the similar effect as that of total pressure. Figures 5, 6, and 7 conclude that the condition favorable for the traditional reactor, i.e., high temperature and low pressure, is applicable for the operation with membrane reactors.

\section{NUMERICAL METHOD}

The tubular membrane reactor is approximated by reactors in series. The number of reactors required to achieve an acceptable accuracy can be determined with a convergence test. Generally, the more number of reactors are selected, the more accurate the simulated results will be. For a typical operating condition, 2 to 20 reactors are selected here to test the convergence of numerical calculation. Figure 8 shows that about 8 reactors are required to give a converged conversion ratio for both conditions with and without vacuum in the permeate side. In this study, 10 reactors are selected for most of the calculation to insure the accuracy of the simulated results. 


\section{DISCUSSIONS}

The advantage of using membranes is that hydrogen can be removed in situ during debydrogenation. Hence the siald of styrene can be higher than that of the thermadynamic equilibrium (Figures 6-8). With the help of permeate side vacuum, an even higher conversion can be achieved because hydrogen in reject is removed more efficiently than those without permeate side vacuum.

Figure is shows that conpersion reaches a maximum at the surface area of $0.6 \mathrm{M}^{2}$ for the condition without vacuum at the permeate side. At this point, the partial pressure of hydrogen is equal on the permeate and the reject side, no more hydrogen oan be removed to the permeate to enhance the dehydrogenation. One should note that the conversion decreases slightly with surface area greate: then $0.6 \mathrm{M}^{2}$.

When vacuum is applied to the permeate side, it is expected that the reaction should resch $100 \%$ conversion. Ethylbenzene, like hydrogen, permeates from the reject although at a much slower rate. Some reactants will permeate through the membrane before dehydrogenation takes place. Therefore, the conversion is improved further by vacuum; but it can not reach 100\%.

\section{LIMITATIONS OF MODEL}

\subsection{Side Reactions}

As discussed in the assumption, only simple dehydrogenation without any side reactions is considered in this study. The selectivity of styrene in the industrial operation ranges from $60 \%$ to $95 \%$, depending on temperature, pressure of the operating condition, and converaion ratio [5]. Major side reaction products includes xylene, toluene, benzene, etc. The side reaction is ignored to simplify the simulation. Since the selectivity can be as bigh as $95 \%$, an assumption like this is realistic for the preliminary analysis. Once the experimental data are collected, the model will be modified to include the side reaction for the purpose of process optimization and development.

\subsection{Isothermal Condition}

Because of the endothermic nature of dehydrogenation, the reaction can be operated under either adiabatic or isothermal depending upon any heat input or not. Both processes have been practiced commercially. The membrane reactor can be designed to be suitable for both operations. In the lab operation, an isothermal condition will be performed. Thus, an isothermal condition is selected in this simulation for directing the design of our experimental study. In the future the model will be modified to include the energy balance for both isothermal and adiabatic conditions since energy consumption will be one of the key considerations in this study. 


\subsection{Validity of Knudsen Diffusion}

Knudsen equation used in this study is valid under the condition that Knudsen diffusion dominates. The rule of thumb is that the ratio of mean free path to pore diameter is larger than 10 [5]. Table 4 shows the mean free path of major components involved: hydrogen, ethylbenzene, styrene, and nitrogen. For a $40 \AA$. membrane, the transport mechanism is within the valid range of Knudsen equation. Further, our experimental results on gas separations are consistent with the prediction based on Knudsen diffusion [6]. However, the program does not discriminate this constraint. Since mean free path is a function of molecular weight, pressure, and temperature, false result may occur if the ratio of mean free path to pore diameter is not carefully examined before using this program.

\subsection{Lecal Equilibrium Conversion}

The tubular membranc reactor is approximated by completely stirred tank reactors in series. Thus, a local equilibrium is assumed throughout the entire tubular reactor. Since the reactor is likely to be operated at the tubulent flow region, the gas component in the tubular reactor could be well mixed. A local equilibrium assumption is valid if the reaction rate is sufficiently fast and the catalytic surface area is sufficient. The former is dependent upon the operating temperature and concentration for a given catalyst, while the latter is determined by the surface area to volume ratio in a membrane reactor. An effectiveness factor can be determined once the experimental data are available. The factor can be incorporated into the model easily to account for the discrepancy of the assumption. The effectiveness factor will be useful information in the design of of the membrane reactor configuration, which will be studied in the second and third year.

\section{REFERENCES}

[1] Boundy, R. H., Boyer, R. F., and Stoesser, S. M., "Styrene, Its Polymers, Copolymers, and Derivatives," Chapter 3, Fp. 71, American Chemical Society Monograph Series, Reinhold Publishing Co. (1952).

Ruthven, D. M.., "Principles of Adsorption and Adsorption Processes," John Wiley \& Sons, pp. 136, (1984).

[3] Ruthven, D. M., "Principles of Adsorption and Adsorption Processes," John Wiley \& Sons, pp. 140 (1984).

[4] Reid, R. C., Trausnitz, J. M., and Poling, B. E., "The Properties of Gases and Liquids," pp. 420, 4th ed., McGraw Hill (1987).

[5] Kirt-Othmer, "Encyclopedia of Chemical Technology," pp. 782, Vol. 21, 3rd Ed., John Wiley \& Sons (1978).

[6] Bhave, R. R., etc., Progress Report for High Temperature Catalytic Membrane Reactors, DE-FC07-881D12778, Alcoa Separations Technology Division, 3/10,89. 


\section{Tables \& Figures}


TABLE 1

Critical Properties and Operation Conditions

\begin{tabular}{lcccc} 
& $\mathrm{H}_{2}$ & Ethylbenzene & Styrene & $\mathrm{N}_{2}$ \\
\hline $\mathrm{Tc}(\mathrm{K})$ & 33.2 & 617.2 & 647.0 & 126.2 \\
$\mathrm{Pc}$ (atm) & 12.8 & 35.5 & 39.4 & 33.5 \\
\hline $\mathrm{T}(\mathrm{K})$ & $773-923$ & $773-923$ & $773-923$ & $773-923$ \\
$\mathrm{P}($ atm) & $0.0-0.5$ & $0.5-0.0$ & $0.0-0.5$ & $0.8-2.0$ \\
\hline $\mathrm{Tr}$ & $23.3-27.8$ & $1.3-1.5$ & $1.2-1.4$ & $6.1-7.3$ \\
$\mathrm{Pr}$ & $0.0-0.04$ & $0.02-0.0$ & $0.0-0.01$ & $0.02-0.06$ \\
$\mathrm{Z}$ & $1-1$ & $0.99-1$ & $1-0.99$ & $1-1$ \\
\hline
\end{tabular}

Total pressure: 1-2.5 atm, 20\% EB, $80 \% \mathrm{~N}_{2}$

$\mathrm{Z}=\mathrm{PV} / \mathrm{RT}$, compressibility factor 
TABLE 2

Composition of Membrane Separation

\begin{tabular}{|c|c|c|c|c|c|c|c|c|c|c|c|}
\hline & \multicolumn{5}{|c|}{ Permeate } & \multicolumn{5}{|c|}{ Beject } & \multirow{2}{*}{$\begin{array}{c}\text { Conversion } \\
(\%)\end{array}$} \\
\hline & Flow & $E B$ & SI & $\mathrm{H2}$ & N & Flow & EB & ST & $\mathrm{H}^{2}$ & $N 2$ & \\
\hline $700 \mathrm{~K}$ & 0.49 & 13 & 2 & 4 & 80 & 0.32 & 21 & 5 & 1 & 73 & 15.6 \\
\hline $800 \mathrm{~K}$ & 0.36 & 8 & 6 & 13 & 72 & 0.39 & 11 & 12 & 3 & 74 & 47.8 \\
\hline $900 \mathrm{~K}$ & 0.35 & 3 & 10 & 25 & 63 & 0.36 & 3 & 19 & 4 & 74 & 83.1 \\
\hline
\end{tabular}

Feed composition: $20 \% \mathrm{~EB}, 80 \% \mathrm{~N}_{2}$

Feed rate: $\quad 700 \mathrm{~K}, 0.783 \mathrm{~mole} / \mathrm{s}\left(0.03 \mathrm{M}^{3} / \mathrm{s}\right)$

$800 \mathrm{~K}, 0.685 \mathrm{~mole} / \mathrm{s}\left(0.03 \mathrm{M}^{3} / \mathrm{s}\right)$

$900 \mathrm{~K}, 0.609 \mathrm{~mole} / \mathrm{s}\left(0.03 \mathrm{M}^{3} / \mathrm{s}\right)$ 
TABLE 3

Composition of Membrane Separation with Permeate Vacuurm

\begin{tabular}{|c|c|c|c|c|c|c|c|c|c|c|c|}
\hline & \multicolumn{5}{|c|}{ Permeate } & \multicolumn{5}{|c|}{ Beject } & \multirow{2}{*}{$\begin{array}{c}\text { Conversion } \\
(\%)\end{array}$} \\
\hline & $\begin{array}{c}\text { Flow } \\
\text { (Mole/s) }\end{array}$ & EB & $S I$ & $\frac{H 2}{10)}$ & $N$ & $\begin{array}{c}\text { Flow } \\
\text { (Mole/s) }\end{array}$ & $E B$ & $S T$ & $\frac{H 2}{1}$ & $N 2$ & \\
\hline $700 \mathrm{~K}$ & 0.66 & 12 & 3 & 5 & 81 & 0.15 & 30 & 10 & 0 & 60 & 20.6 \\
\hline $800 \mathrm{~K}$ & 0.63 & 6 & 7 & 13 & 74 & 0.14 & 12 & 26 & 0 & 61 & 59.1 \\
\hline $900 \mathrm{~K}$ & 0.58 & 2 & 10 & 19 & 69 & 0.14 & 1 & 36 & 0 & 63 & 90.3 \\
\hline
\end{tabular}

Feed composition: $20 \% \mathrm{~EB}, 80 \% \mathrm{~N}_{2}$

Feed rate: $\quad 700 \mathrm{~K}, 0.783 \mathrm{~mole} / \mathrm{s}\left(0.03 \mathrm{M}^{3} / \mathrm{s}\right)$

$800 \mathrm{~K}, 0.685 \mathrm{~mole} / \mathrm{s}\left(0.03 \mathrm{M}^{3} / \mathrm{s}\right)$

$900 \mathrm{~K}, 0.609 \mathrm{~mole} / \mathrm{s}\left(0.03 \mathrm{M}^{3} / \mathrm{s}\right)$ 
TABLE 4

Mean Free Path at 1 atm

\begin{tabular}{lrcc} 
& & & \\
& $298 \mathrm{~K}$ & $673 \mathrm{~K}$ & $923 \mathrm{~K}$ \\
\cline { 2 - 2 } $\mathrm{H}_{2}$ & 1018 & 2595 & 3727 \\
$\mathrm{~EB}$ & 126 & 429 & 666 \\
$\mathrm{ST}$ & 125 & 430 & 670 \\
$\mathrm{~N}_{2}$ & 630 & 1733 & 2467 \\
\hline
\end{tabular}

unit: $\AA$ 


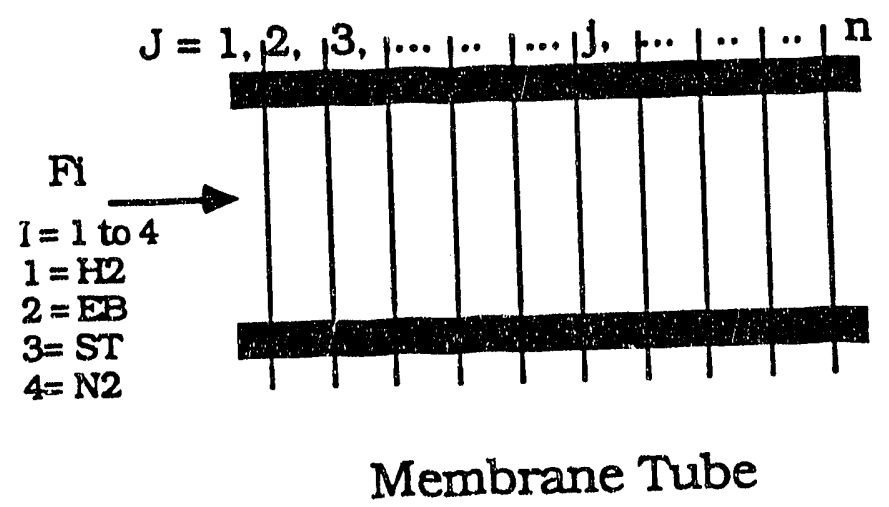

Figure 1 Separation of Membrane Reactor into " $n$ " Number of Stages 


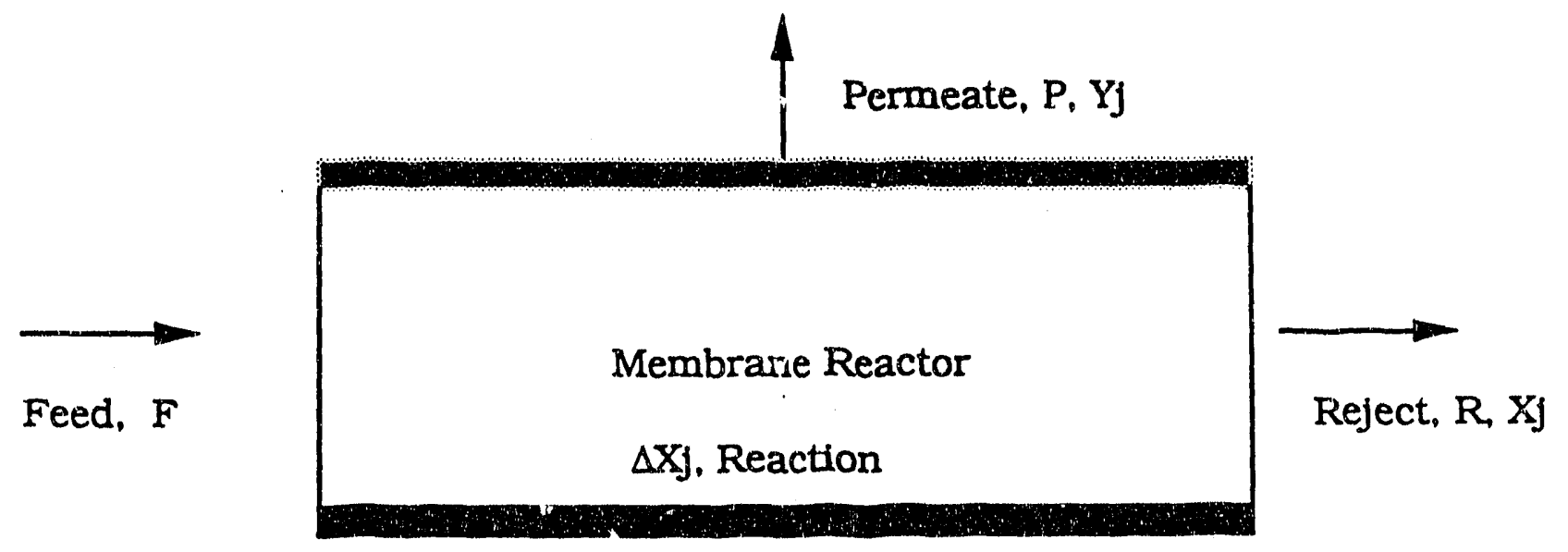

Figure 2 Material Balance of Given Stage, $j$ 


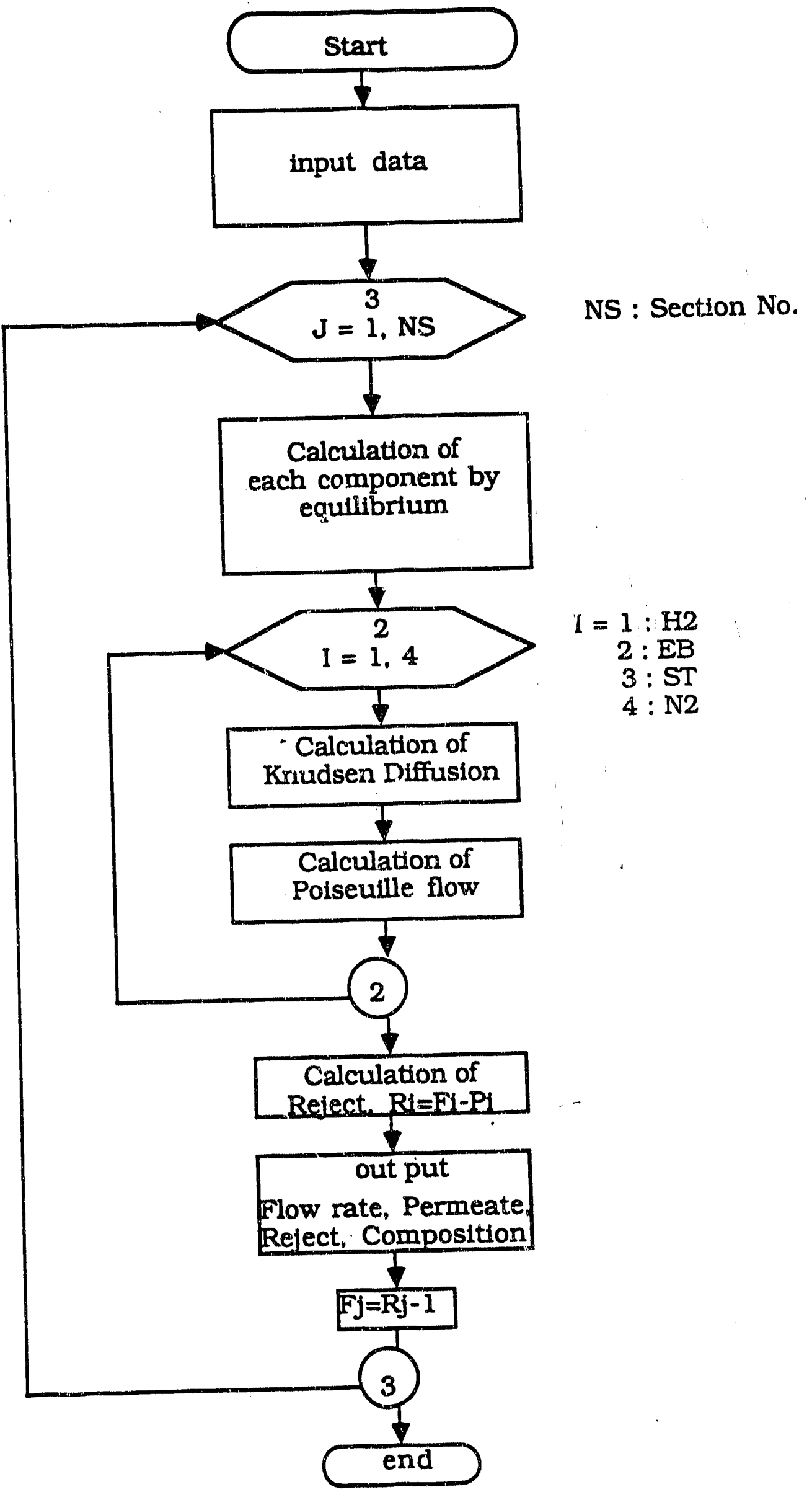

Figure 3 Flow Chart of Computer Program 


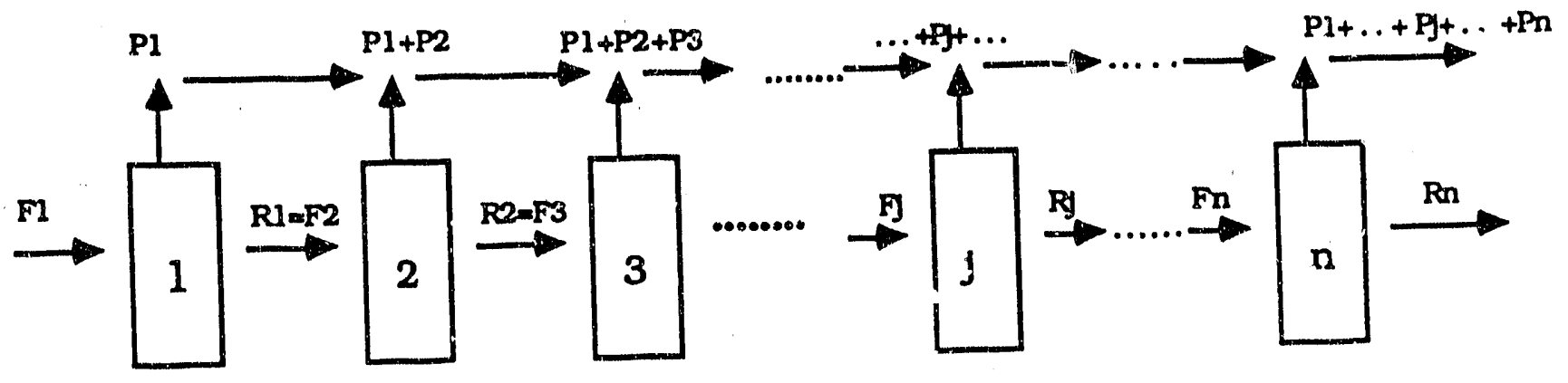

Option a : No Vaclium at Permeate Side

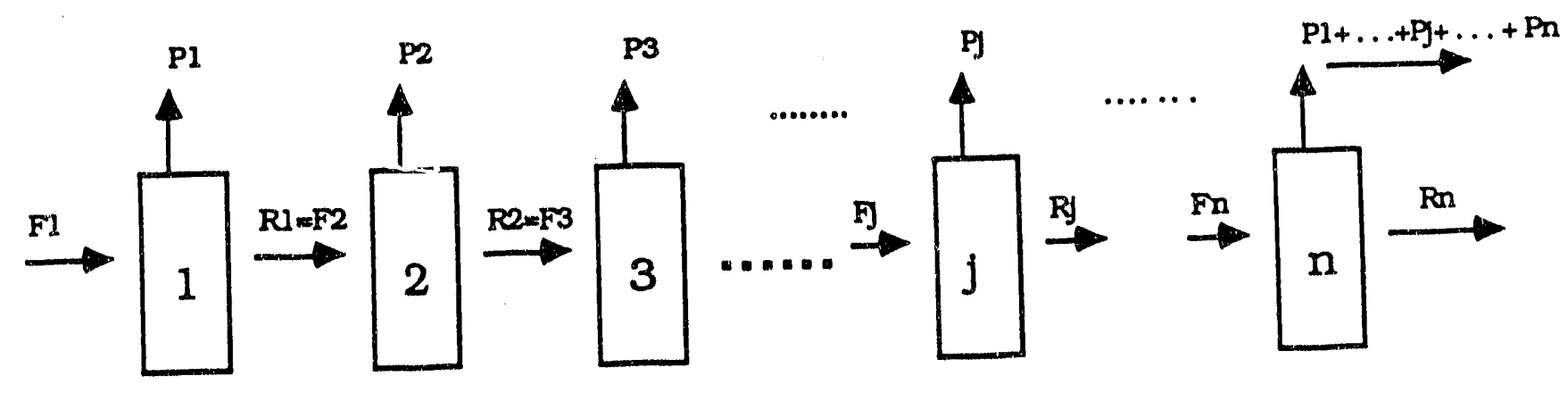

Option b : Vacuum at Permeate Site

Figure 4 Sectional Calculation Diagram 

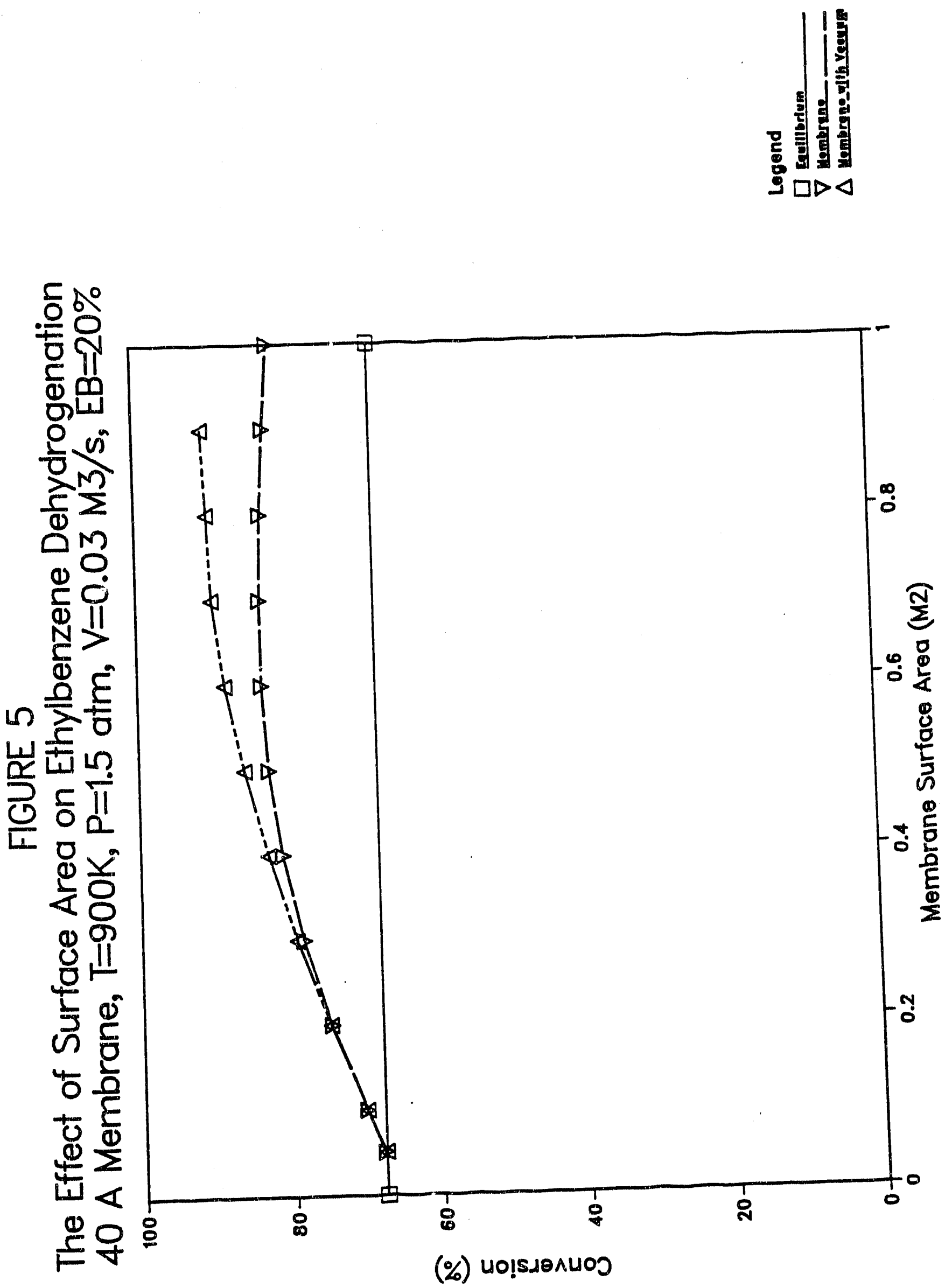

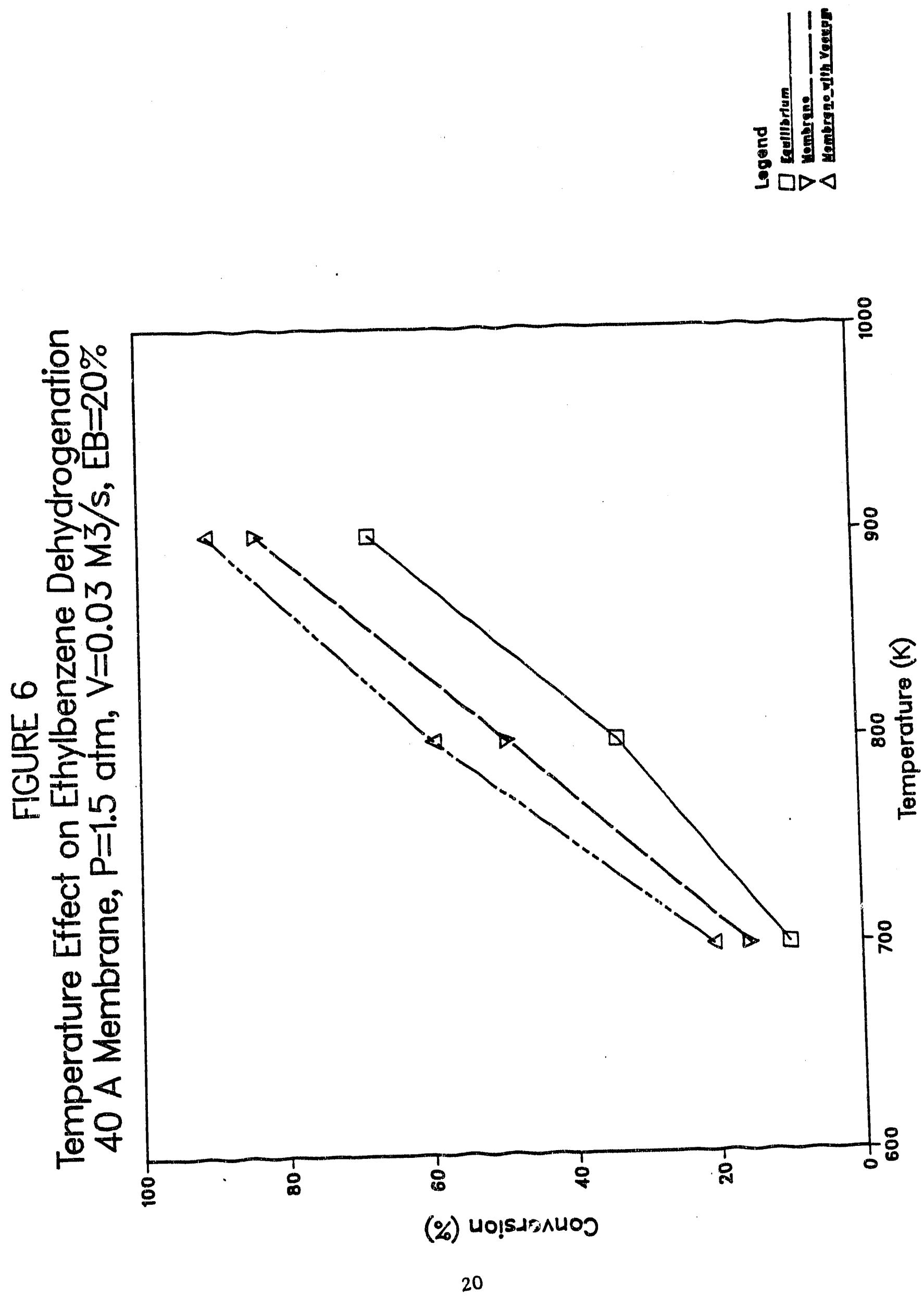

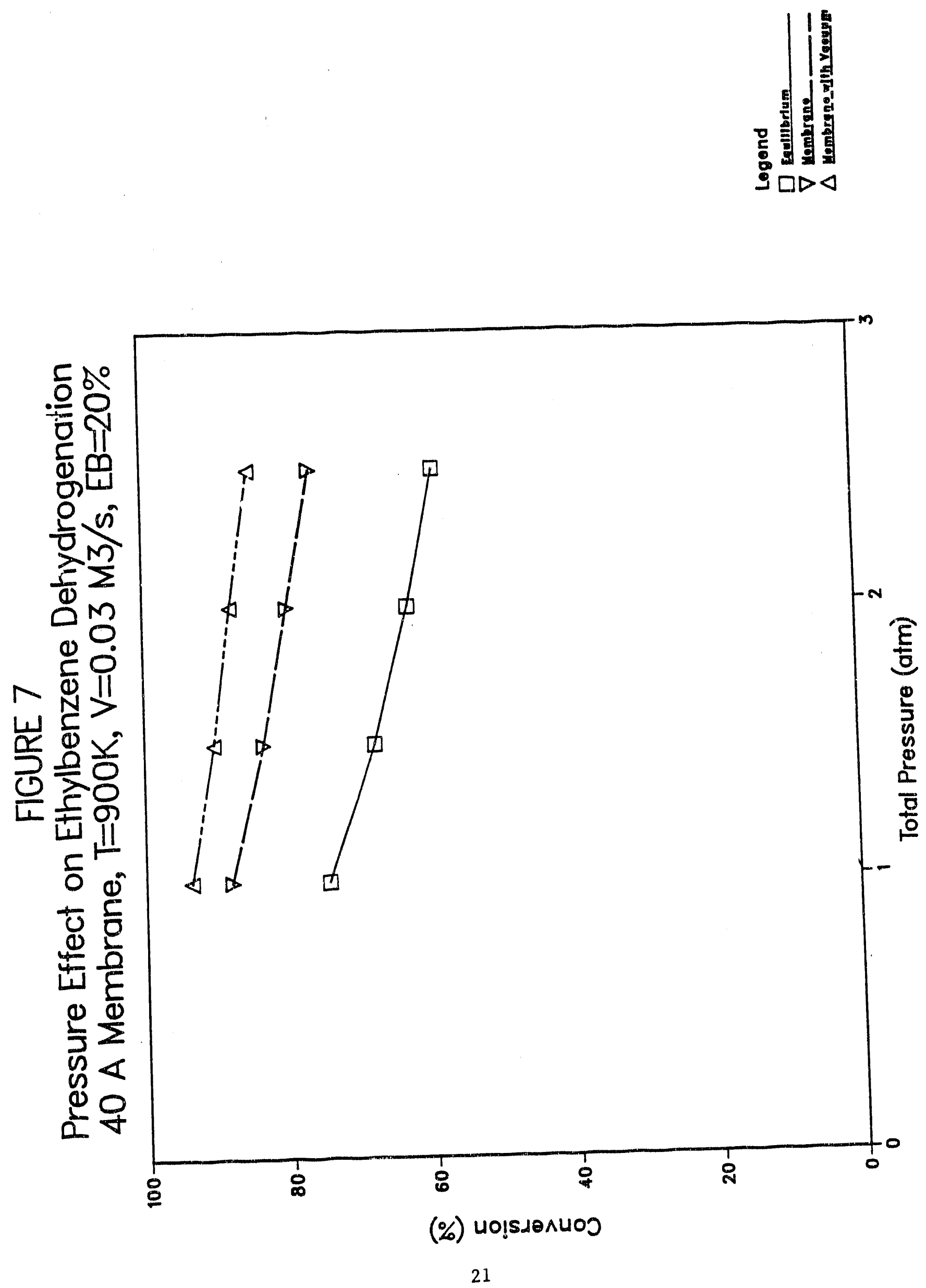

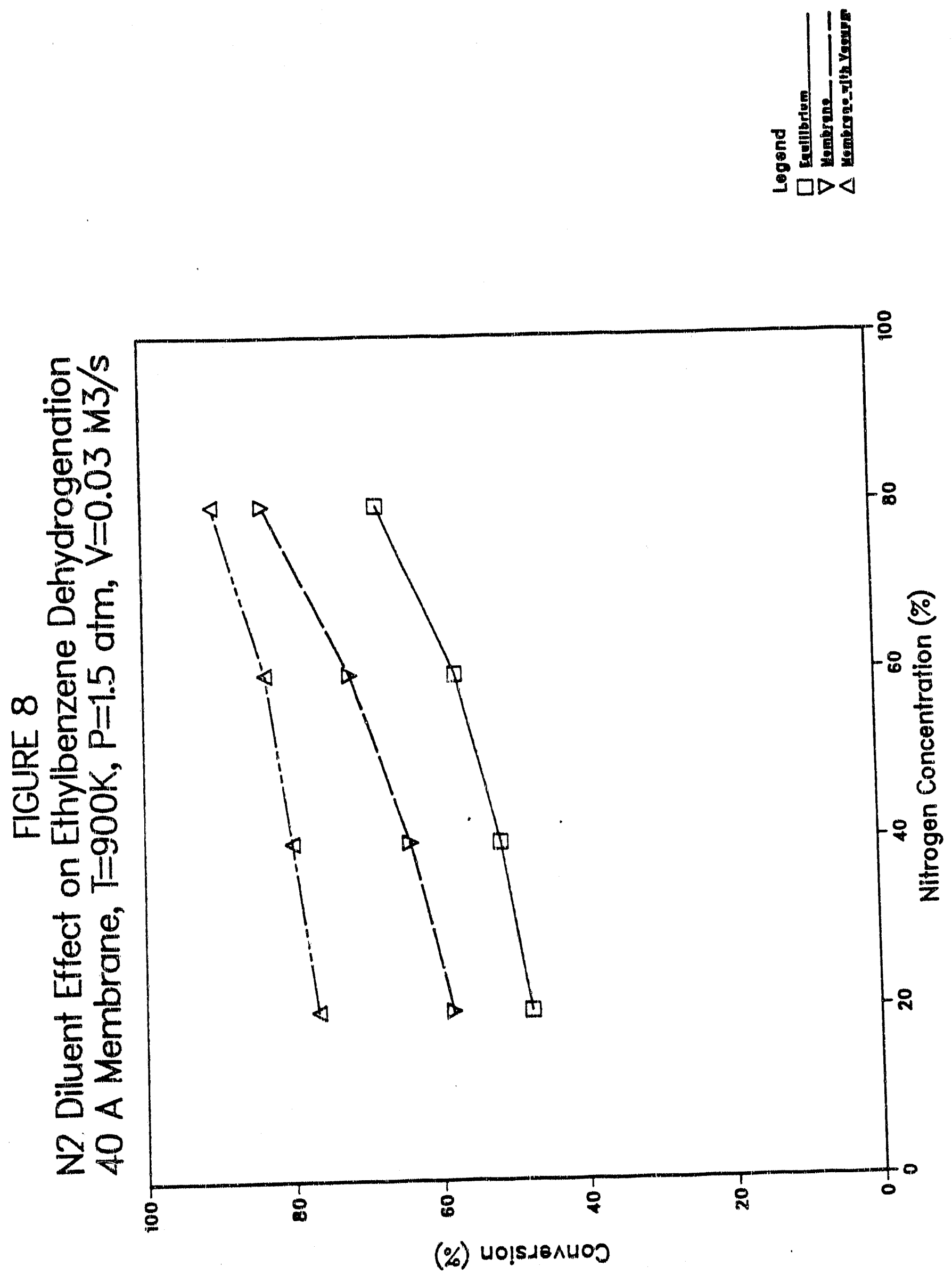

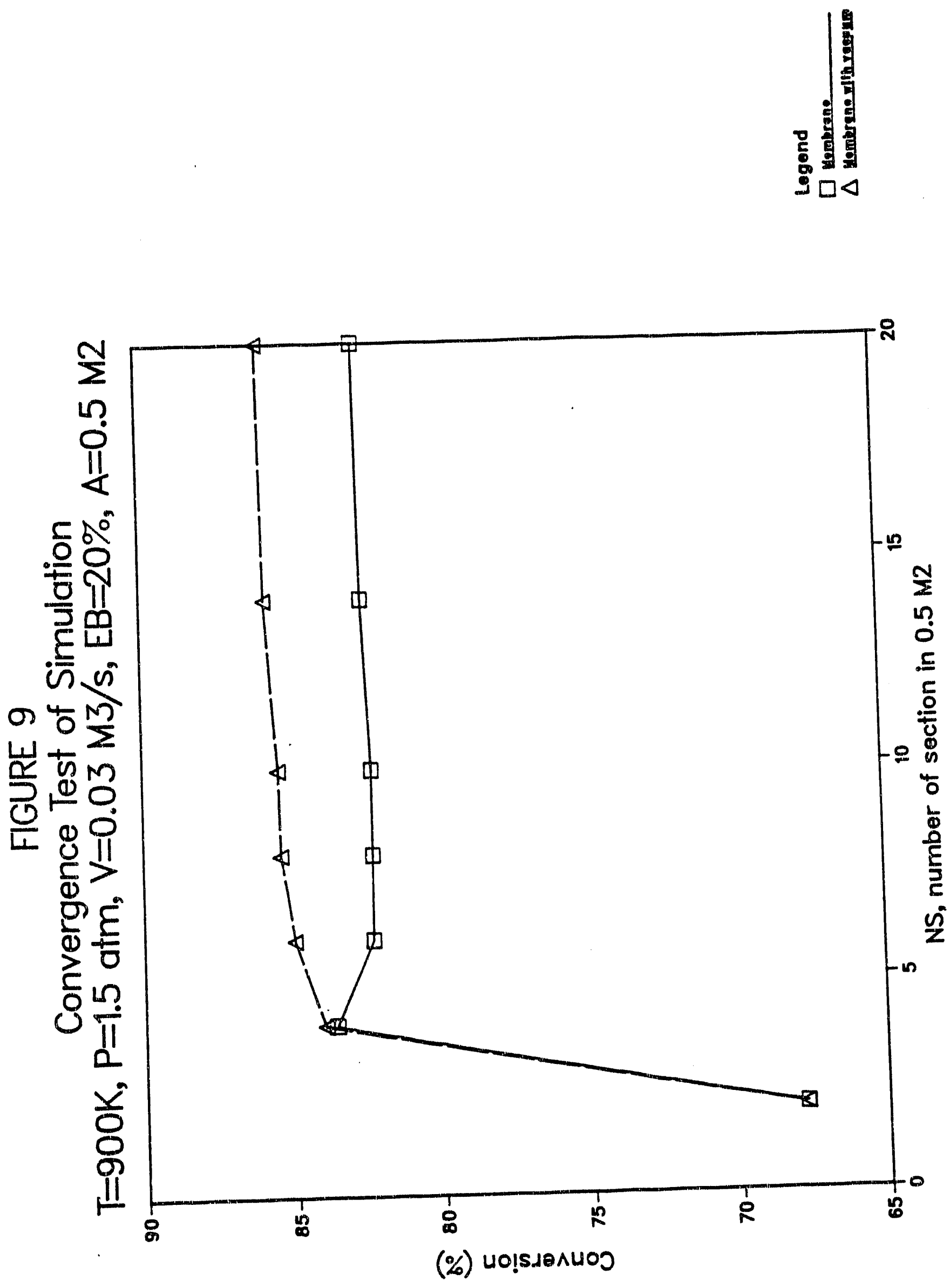


\section{Appendix}




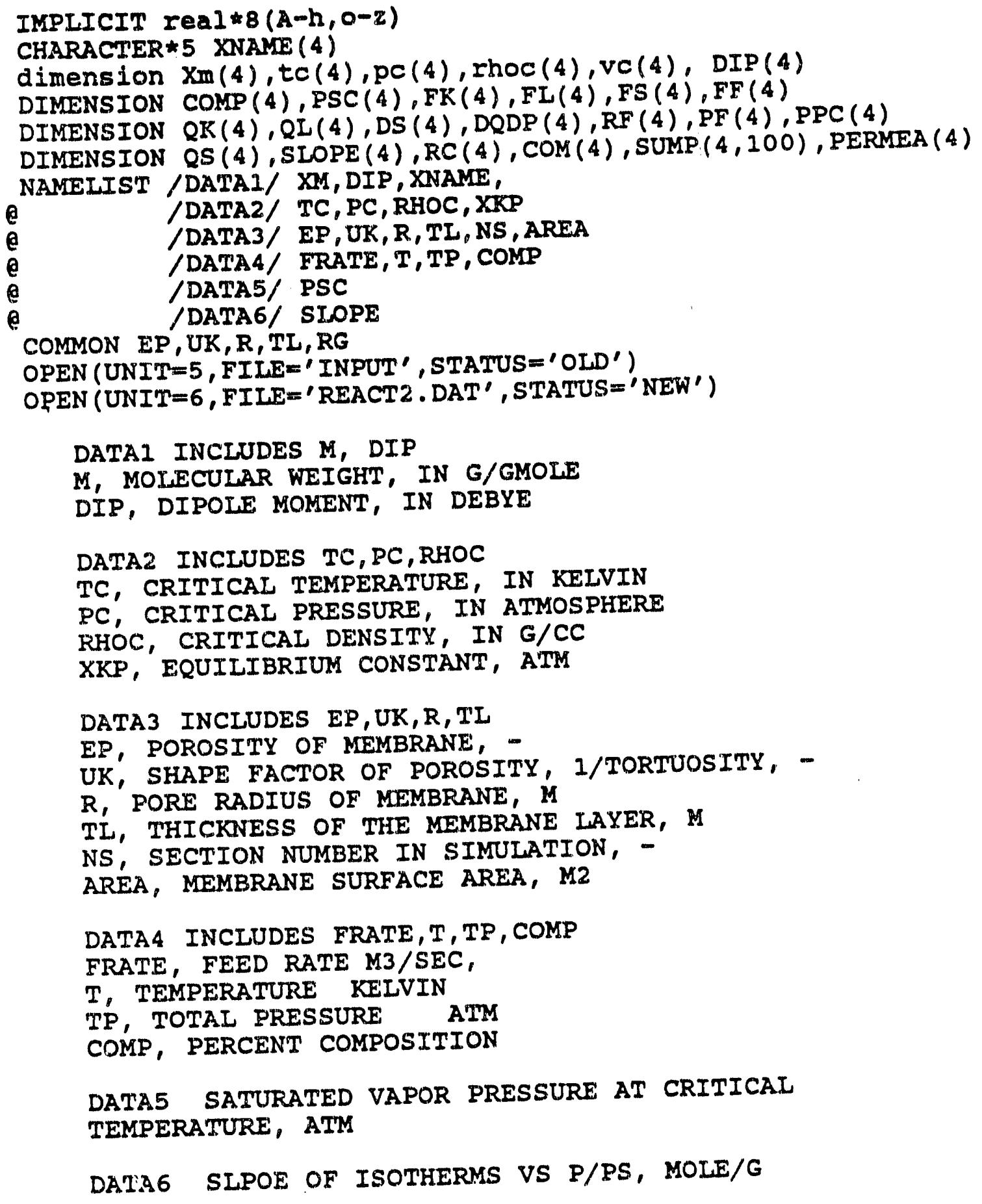

READ IN DATA

$\operatorname{READ}(5, \operatorname{DATA2})$

READ (5, DATAI)

$\operatorname{READ}(5$, DATA3)

READ (5, DATA4)

READ (5, DATA5)

$\operatorname{READ}(5$, DATA6)

$\mathrm{RG}=8.306$

$\mathrm{RHO}=2.9 \mathrm{E} 6$

WRITE THE TITLE

WRITE $(6,10) \quad R * 2$. E10, AREA

10 FORMAT $(/ / /, 7 X, F 6.1, "$ A FŪE SIZE MHERANE WTITH CATALYTIC 
ERXN', //,25X,' SURFACE AREA =',F10.4,' M2')

\section{INITIALIZE THE VARIABLES}

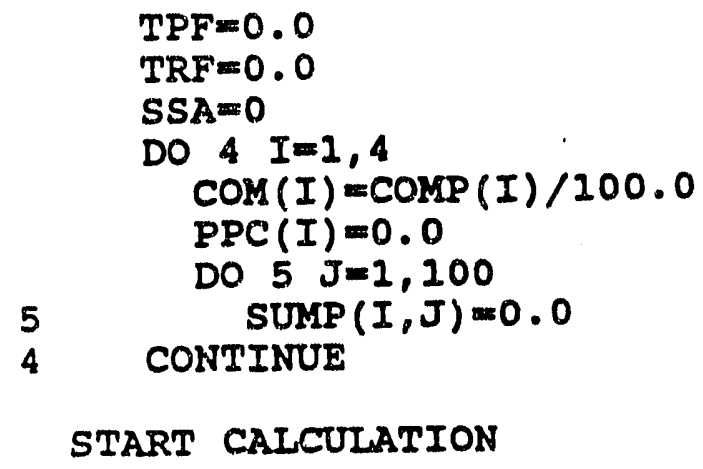

DO $7 \quad I=1,4$ $\operatorname{COM}(I)=\mathrm{RC}(I)$ 


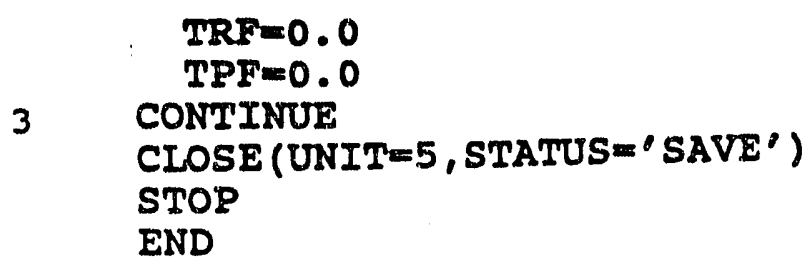

FUNCTION X IAMINAR (XM, RHOC, TC, PC, DIP, T, PM) IMPLICIT REAL $8(A-\mathrm{H}, 0-\mathrm{Z})$

FUNCTION SURFACE (PSC, TC, SLOPE, RHO, T)

IMPLICIT REAI*8 $(\mathrm{A}-\mathrm{H}, \mathrm{O}-\mathrm{Z})$

COMMON EP, UK, R, TL, RG

$\mathrm{DS}=1.345 \mathrm{E}-6 * \operatorname{EXP}(-3142.177 / \mathrm{T})$

$\mathrm{PS}=\mathrm{PSC} *(\mathrm{~T} / \mathrm{TC}) \star \star 2$

$D Q D P=S I O P E /(P S * 1.013 E 5)$

SURFACE $=U K *$ RHO * $(1-E P) * D S * D Q D P / T L$

RETURN

END

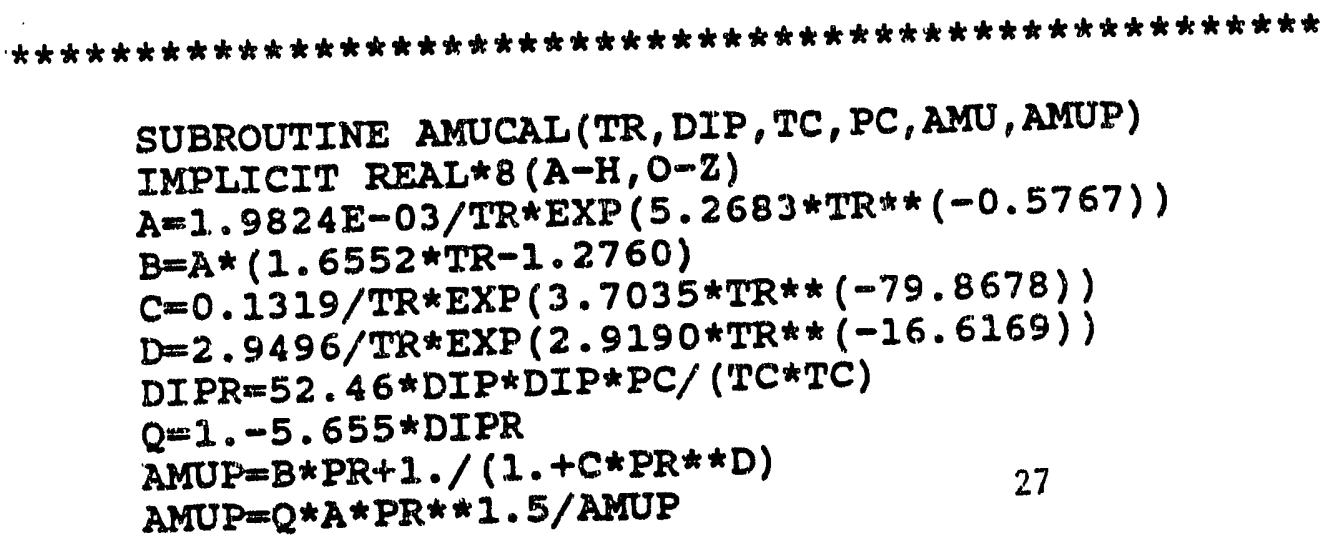


AMUP $=A M U *(1 .+$ AMUP $)$

RETURN

END

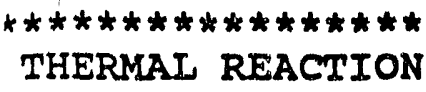

SUBROUTINE REACTION (XKP, COM, TP, NS, TNN)

IMPLICIT REAL*8 (A-H,O-Z)

DIMENSION COM (4)

$\mathrm{XEB}=\mathrm{COM}(1) * \mathrm{TNN} / \mathrm{NS}$

$X S T Y=\operatorname{COM}(2) * T N N / N S$

$\mathrm{XH} 2=\operatorname{COM}(3) \star \mathrm{TNN} / \mathrm{NS}$

$\mathrm{XN} 2=\operatorname{COM}(4) * \mathrm{TNN} / \mathrm{NS}$

$\mathrm{D}=\mathrm{XKP} / \mathrm{TP}$

$A=1+D$

$B=X H 2+X S T Y+D *(X H 2+X S T Y+X N 2)$

$C=-X H 2 * X S T Y+D * X E B *(X E B+X H 2+X S T Y+X N 2)$

DELTE $X=(-B+S Q R T(B * B+4 * A * C)) /(2 * A)$

$T N N=(\bar{X} E B+X S T Y+X H 2+D E L T A+X+X N 2) * N S$

$\operatorname{COM}(1)=\left(X E B-D E L T A \_X\right) * N S / T N N$

$\operatorname{COM}(2)=(X S T Y+D E L T A-X) * N S / T N N$

$\operatorname{COM}(3)=\left(X H 2+D E I T A \_\bar{X}\right) * N S / T N N$

$\operatorname{COM}(4)=\left(X_{N} 2\right) * N S / T \bar{N} N$

RETURN

END 
\$DATA2 TC $=617.2,647.0,33.2,126.0$

$\mathrm{PC}=35.54,39.39,12.83,33,5$

RHOC $=0.2839,0.2888,0.031,0.3110$

XKP=0.375\$END

\$DATAI XNAME='EB ','STY ','H2 ','N2 ',

$X M=106.168,104.152,2.016,28.02$

$D I P=0.4,0.1,0.0,0.0$ SEND

\$DATA3 EP $=0.5, U K=0.339, R=20 . E-10, T L=5.0 E-06, N S=20, A R E A=1.0 \$ E N D$

\$DATA4 FRATE $=0.03, T=900.0, T P=1.5$,

COMP $=20.0,0.0,0.0,80.0 \$ E N D$

\$DATA5 PSC $=35.54,39.39,12.83,33.46$ \$END

\$DATA6 SLOPE $=0.0,0.0,0.0,0.0 \$ E N D$ 

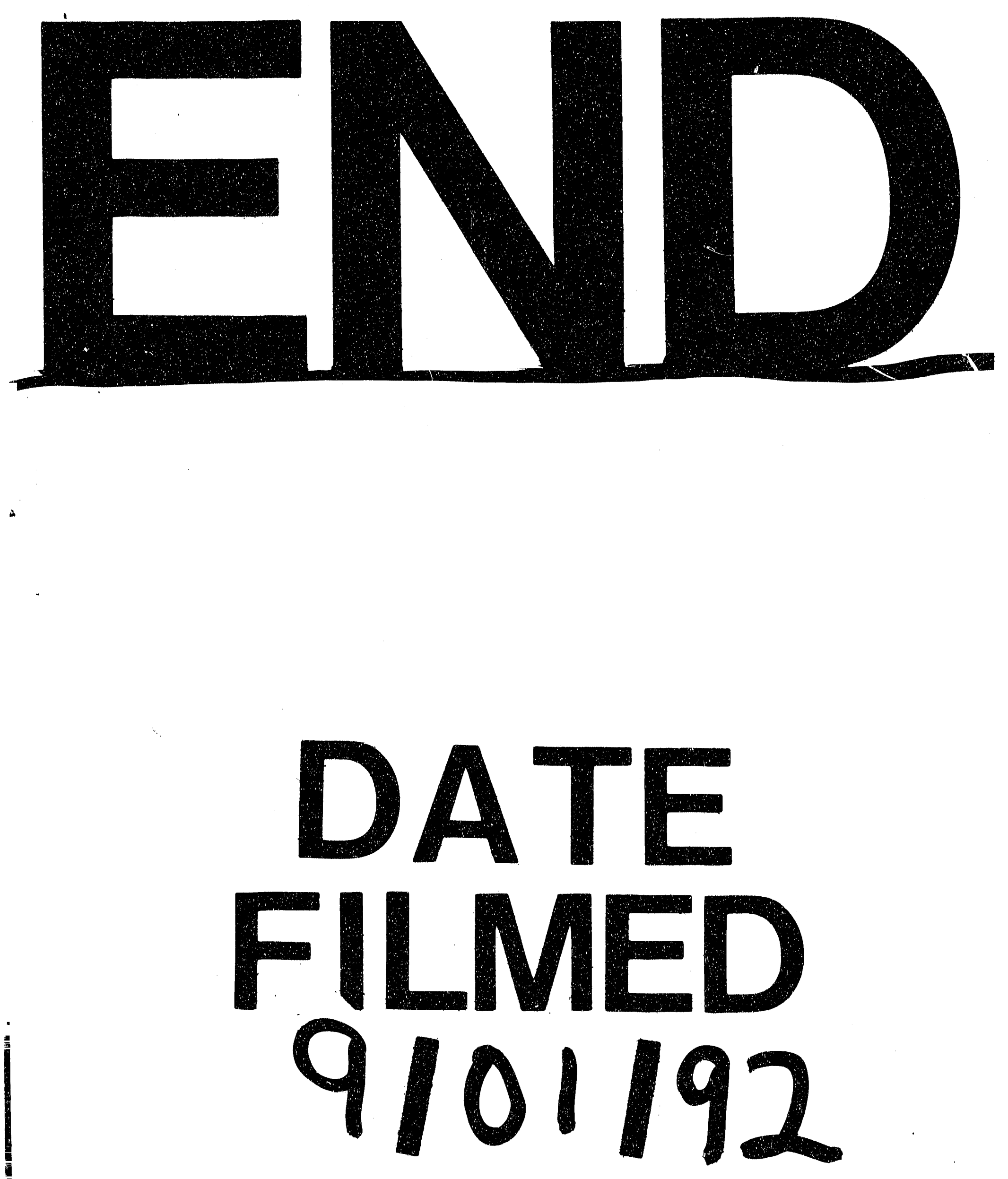
, 